Mustafaev R.K.

\title{
IDENTIFICATION OF ILLEGAL TRAFFICKING IN NARCOTIC DRUGS AND PSYCHOTROPIC SUBSTANCES DURING REGULAR AND OPERATIONAL-SEARCH MEASURES
}

\begin{abstract}
Преступные деяния в сфере незаконного оборота наркотических средств и психотропных веществ выявляются преимущественно по результатам оперативно-розыскной деятельности, в связи с чем, огромное значение для раскрытия преступления имеет оперативно-розыскная информация. Результаты оперативно-розыскной деятельности являются мощным инструментом в профилактике преступлений, связанными с незаконным сбытом наркотических средств и психотропных веществ. Однако, наличие ошибок и нарушений закона зачастую приводит к прекращению уголовного преследования в отношении реально виновных лиц или же ее смягчению. В этой связи необходимо использование рекомендаций для своевременной профилактики ошибок и нарушении закона со стороны сотрудников, осуществляющих оперативно-розыскную деятельность в процессе выявлении незаконного оборота наркотических средств и психотропных веществ при проведении режимных и оперативно-розыскных мероприятий, а также их устранения законными способами.
\end{abstract}

Ключевые слова: незаконный оборот, наркотические средства, психотропные вещества, оперативно-розыскная деятельность.

Criminal acts in the sphere of illicit trafficking in narcotic drugs and psychotropic substances are detected mainly based on the results of operationalsearch activities, in this connection, operational-search information is of great importance for solving a crime. The results of operational-search activities are a powerful tool in the prevention of crimes related to the illegal sale of narcotic drugs and psychotropic substances. However, the presence of errors and violations of the law often leads to the termination of criminal prosecution against the really guilty persons or its mitigation. In this regard, it is necessary to use the recommendations for the timely prevention of errors and violations of the law by employees carrying out operational-search activities when detecting illegal trafficking in narcotic drugs and psychotropic substances during security and operational-search activities, as well as their elimination by legal means.

Keywords: illegal traffic, narcotic drugs, psychotropic substances, operational-search activity.

Работники правоохранительных органов должны учитывать, что в тех местах, где находились лица, употребляющие наркотические средства или психотропные вещества, имеются всегда практически оставленные вещества и предметы, с помощью которых происходит приготовление наркотических средств в бытовых условиях. Кроме этого, имеются еще и запахи, концентрирующиеся в помещениях, имеющие непривычные оттенки, по которым можно определить вид применяемого наркотического средства.

Используя гласные силы и средства, не всегда удается выявить лиц, осуществляющих незаконный оборот наркотиче- 
ских средств или психотропных веществ. В связи с чем, актуальной стала проблема, связанная с изучением поведения лиц, употребляющих наркотические средства и психотропные вещества в местах лишения свободы, и выявлением осужденных в исправительных учреждениях. Статистические данные разъясняют некоторые вопросы влияния образа жизни и наркотизации до осуждения на поведение в учреждениях уголовно-исполнительной системы, но вместе с тем, не получившие единообразного решения в теории и практике противодействия незаконному обороту наркотических средств или психотропных веществ.

Следует обратить внимание на то, что ранее исследователи отмечали значительное число лиц, употребляющих наркотические средства, приобщается в местах лишения свободы. Так, по данным Ш.Н Галиулина и С.Н. Пономарева, удельный вес таких лиц составил около 25\% [3, с. 11]. Вместе с тем, результаты проведенного автором социологического исследования не подтверждают данный результаты, их число составляет $18 \%$.

В условиях изоляции, как правило, меньше возможностей для приобретения, потреблении, хранения и других действий с наркотическими средствами, чем на свободе, следовательно, приобщение к потреблению наркотических средств осужденных является основополагающим фактором в формировании патологической личности и в совершении данными лицами преступлений в исправительных учреждениях, так и после освобождении из исправительною учреждения. Особую сложность в работе с осужденными представляет выявление лиц, употребляющих наркотические вещества. Оперативно-розыскная профилактика незаконного оборота наркотических средств и психотропных веществ в исправительных учреждениях состоит из нескольких этапов: 1) сбор информации о лицах, способных совершить противоправное деяние, достигается проведением оперативно-розыскных мероприятий посредством наблюдения, опроса, наведением справок, а также перепроверкой полученных сведений; 2) документирование фактов и обстоятельств, действий и различных поступков лиц, отбывающих наказание за незаконный оборот наркотических средств и психотропных веществ; 3) реализация на основе полученных данных, мероприятий профилактического характера включающие в себя: а) сдерживание объектов оперативно-розыскной деятельности от реализации преступных намерений; б) постановка на оперативный учет, с последующим проведением в отношении таких лиц воспитательной работы.

Наиболее распространенным способом передачи наркотических средств и психотропных веществ на территорию колоний является их «переброс», то есть когда виновное лицо перебрасывает сверток с наркотическим средством или психотропным веществом и иными запрещенными предметами через ограждение, а затем его подбирают осужденные. Но имеют место и случаи, когда пришедшие на свидание к осужденному лица пытаются пронести наркотики при себе, а иногда и в себе [5].

Сотрудники ФСИН в г. Санкт Петербурге обнаружили накануне сразу две попытки передачи наркотических средств заключенным. Обе запрещённые «передачи» не пропустили во время досмотра. В первом случае подозрения у сотрудников вызвала упаковка сыра. При её досмотре сотрудники обнаружили там посторонний объект в виде твердого коричневого вещества. Во второй ситуации проверка установила, что это был «гашиш» массой около двух с половиной грамм. У сотрудников зоны досмотра не вызвали доверия вафли. В упаковке со сладостями ухищренным способом разместились несколько полиэтиленовых свертков с серым порошком. Его изъяли и передали на изучение. Оказалось, что это был психотропное средство «амфетамин» массой 1,72 грамма. По факту данных случаев были организованы соответствующие проверки [2].

Каждый сотрудник исправительного учреждения должен знать ориентирующие признаки начала процесса наркотизации. Это могут быть необычная для хорошо известного человека работоспособность или наоборот, резкое снижение активности, не оправданные внешними данными раздражителями агрессивные вспышки или расслабленность. Особенно отличается поведение человека в период наркотического истощения, которое весьма трудно не заметить. В это время отмечается двигательная активность, злобность, потливость, дрожание конечностей и психические расстройства. Если же человек принимает наркотические средства продолжительное время, то у него появляются такие характерные внешние признаки, как истощение, облысение, морщины, выпадение зубов, желтоватый оттенок кожи.

Необходимо также обращать внимание на повышение активности дружеских жестов, появление в тумбочках шприцев, 
игл, нагревательных приборов, следов уколов на руках и ногах, пятен крови на белье. Что касается общей характеристики поведения осужденных-наркоманов, то около половины из них $(45,9$ \%) являются злостными нарушителями режима [1, с. 59], на что определенное внимание оказывает и вид потребляемых до осуждения наркотических средств или психотропных веществ. Результаты проведенного автором социологического исследования указывают на снижение, 8\% подвергались дисциплинарным взысканиям, $11 \%$ затруднились ответить. Начальникам отрядов исправительных учреждений целесообразно иметь памятку о поведенческих характеристиках и основных диагностических признаках лиц, осужденных за незаконный оборот наркотических средств в среде осужденных. Это поможет своевременно выявлять и предупреждать наркотизм. Одной из форм изучения личности наркомана является беседа, в ходе которой следует использовать различные методы.

Димитровградец пытался доставить наркотики в колонию, но был задержан. За совершенное преступление суд приговорил его к 10 годам лишения свободы. Мужчина приобрел у контрагента 80 гр. гашиша и марихуаны, которые попытался передать территорию ИК-3. В ходе специальных мероприятий курьера задержали [4].

Таким образом, оперативные подразделения органов исполняющих наказания, для достижения поставленных задач, используют достаточный набор средств, находящийся в их расположении, который позволяет получать как открыто, так и тайно ту информацию, которая позволяет предупредить распространение данных преступлений в исправительных учреждениях, что становится возможным с помощью оперативно-розыскных мероприятий.

\section{Литература}

1.Алиев В.М. Личность преступника и наркомания. М., 1993. С. 59.

2.В двух исправительных учреждениях Петербурга нашли еду с наркотиками [Электронный ресурс] URL :https://nevnov.ru/489993-v-dvuh-ispravitelnyhuchrezhdeniyah-peterburga-nashli-edu-s-narkotikami(дата обращения: 18 декабря 2020)

3.Галиулин Ш.Н., Пономарев С.Н. Исполнение лишения свободы в отношении наркоманов. Рязань, 1988. С. 11.

4. Димитровградец получил 10 лет за попытку доставить наркотики в колонию.[Электронный ресурс] URL :http://rupor73.ru/lenta-novostej/24028dimitrovgradets-poluchil-10-let-za-popytku-dostavit-narkotiki-v-koloniуu(дата обращения: 19.12. 2020)

5.Наиболее распространенным способом передачи наркотиков на территорию исправительных учреждений является их перебрасывание через ограждение. [Электронный ресурc] URL: https://prokuratura-vrn.ru/?m=14\&viewnews=2046(I fnf(дата обращения: 19.12.2020)

\section{References}

1.Aliyev V.M. Lichnost' prestupnika i narkomaniya. M., 1993. S. 59.

2.V dvukh ispravitel'nykh uchrezhdeniyakh Peterburga nashli yedu s narkotikami [Elektronnyy resurs] URL :https://nevnov.ru/489993-v-dvuh-ispravitelnyhuchrezhdeniyah-peterburga-nashli-edu-s-narkotikami(data obrashcheniya: 18 dekabrya 2020).

3. Galiulin SH.N., Ponomarev S.N. Ispolneniye lisheniya svobody v otnoshenii narkomanov. Ryazan', 1988. S. 11.

4. Dimitrovgradets poluchil 10 let za popytku dostavit' narkotiki v koloniyu. [Elektronnyy resurs] URL :http://rupor73.ru/lenta-novostej/24028-dimitrovgradetspoluchil-10-let-za-popytku-dostavit-narkotiki-v-koloniyu(data obrashcheniya: 19.12. 2020).

5. Naiboleye rasprostranennym sposobom peredachi narkotikov na territoriyu ispravitel'nykh uchrezhdeniy yavlyayetsya ikh perebrasyvaniye cherez ograzhdeniye. [Elektronnyy resurs] URL: https://prokuratura-vrn.ru/?m=14\&viewnews=2046(Ifnf( data obrashcheniya: 19.12 .2020

МУСТАФАЕВ Рашад Камалович, подполковник полиции, заместитель начальника курса факультета подготовки иностранных специалистов Московского университета МВД России им. В.Я. Кикоть. 117997, г. Москва, ул. Академика Волгина, д. 12. E-mal: rashad-85@mail.ru

MUSTAFAEV Rashad Kamalovich, police lieutenant colonel, Deputy Head of the Course of the Faculty of Foreign Studies, Moscow University of the Ministry of Internal Affairs of Russia V.Ya. Kikot. 117997, Moscow, st. Academician Volgin, 12. E-mal: rashad-85@mail.ru 